\title{
A vision for the development of i-campus
}

\author{
Lam-for Kwok
}

\author{
Correspondence: cslfkwok@cityu.edu.hk \\ Department of Computer Science, \\ City University of Hong Kong, Tat \\ Chee Avenue, Kowloon, Hong Kong \\ SAR, PR China
}

\begin{abstract}
The development of a smart campus is part of the development of a smart city. The development of information and communication technologies poses new challenges to teaching and learning. Stakeholders in education will have different requirements on intelligence which in turn requires various supporting technologies. Examples of smart educational systems are given to illustrate the common characteristics of smartness. Essential elements in constructing intelligent campus: data considerations, procedural knowledge and system integration are discussed.

Keywords: Digital campus; Smart campus; Intelligent campus
\end{abstract}

\section{Introduction}

The development in information and communication technology (ICT) never stops. Cloud computing, supercomputer centers, data centers and big data are some of the keywords attracting attention not only from the information technology sector but also from the general public. Such development forms a solid foundation in providing a good infrastructure support to the construction of smart cities. However, the fashionable concept of smart city does not only rely on the investment in the construction of traditional infrastructure like transportation systems but also a huge investment in the construction of the ICT infrastructure in supporting sustainable economic development so as to improving quality of life (Caragliu et al. 2011).

The definition of a smart city varies but in general, it refers to the dynamic integration of digital world and the physical world in which data from various sources are collected automatically in real time. This data captures the changes of states of the physical world which in turn are transmitted to data centers for storage and processing via high speed networks. The data capture relies on a large amount of sensors at various locations; transmission of this large amount of data relies on the Internet or high speed networks; and the storage and processing of this data relies on the use of cloud environment, that is, the virtualization of resources in data centers and supercomputer centers. A smart city is built upon a large amount of system integrations which includes both the digital systems integration and the physical to digital systems integration.

With the aim to improving quality of life of citizens, there are many areas that a local government may want to provide under this smart city framework (Odendal 2003). The development in supporting knowledge economy requires the development of smart education and its associated labor force together with industries for innovation. Smart urban operations include intelligent transportations, green energy utilities,

(c) 2015 Kwok; licensee Springer. This is an Open Access article distributed under the terms of the Creative Commons Attribution License (http://creativecommons.org/licenses/by/4.0), which permits unrestricted use, distribution, and reproduction in any medium, provided the original work is properly credited. 
environmental protection, etc. Efficient governance attempts to improve quality of lives to citizens including efficient and transparent government administration, health care services, and public safety.

Nam and Pardo (Nam and Pardo 2011) identified three core factors, which include technology, human and institution, in making a city smart. The technology factor provides the necessary physical and digital infrastructure for a smart city (Boulton et al. 2012). The human factor provides another layer of infrastructure to the success of a smart city (Winters 2010). Education becomes an important component and has been used as one of the important criteria in performance evaluation of smart cities (Centre of Regional Science and Vienna 2007; Lombardi et al. 2012). Smart education provides citizens with a dynamic learning environment in transforming them into smart workforce. A city cannot be smart if there are insufficient qualified people in providing innovative solutions. The institutional factor provides a good administrative environment on top of these infrastructures with the support of appropriate policies for integrated and transparent governance (Odendal 2003; Yigitcanlar and Velibeyoglu 2008). Smart education is thus closely related to the success, and be an integral part of a smart city.

System integration is vital to achieve efficient governance and information infrastructure is an enabling facilitator for collaboration and engagement (Komninos 2009). The availability of data of different functional areas does not only facilitate the planning of a city but enables various service providers to provide better services to citizens more intelligently. For example, student population of residential areas would affect the planning of schools and in turn affect the planning of transportation. But the availability of actual daily data of student movement might enable service providers in transportation to provide dynamic services to school children even for some ad-hoc events of a school. These data have to be provided by schools via educational authorities. The next question is how these data can be captured, obtained and generated in a school environment.

Intelligent campus (i-campus) refers to a new paradigm of thinking pertaining to a holistic intelligent campus environment which encompasses at least, but not limited to, several themes of campus intelligence, such as holistic e-learning, social networking and communications for work collaboration, green and ICT sustainability with intelligent sensor management systems, protective and preventative health care, smart building management with automated security control and surveillance, and visible campus governance and reporting. Several initiatives have been reported on intelligent campus, ranging from proposing a holistic framework, using cloud and mobile technologies to support learning, improving security management using RFID technology, to better space utilization on campus (Chen et al. 2013; Chen et al. 2011; Hirsch and Ng 2011; Jackson 2006; Ng et al. 2010).

The aim of this paper is to envision the possible ways of intelligent campus development. The remaining sections in this paper discuss the challenges encountered by a traditional campus, the requirements on intelligence by different stakeholders on campus together with some possible research areas; describe some characteristics of smart campus with examples; and discuss the essential elements of the development of intelligent campus.

\section{Intelligent campus}

A campus can be considered traditionally as a piece of land on which buildings of an educational establishment are constructed. There are libraries, classrooms, residential 
halls, student centers, dining halls, and recreation areas. According to Webster Dictionary, Intelligence means the ability to learn or understand or to deal with new or difficult situations; the ability to apply knowledge to manipulate one's environment or to think abstractly as measured by objective criteria; and secret information that a government collects about an enemy or possible enemy. Thus an intelligent campus can be interpreted that a campus which has the ability to response to new situations occurred on campus in its daily operation. In this section, we describe some of the new challenges on campus, the kinds of intelligence in need for different stakeholders, and some of the relating research and development opportunities.

\section{New challenges on campus}

The new development of information infrastructure in campus brings new opportunities to teaching and learning but also poses new challenges to the traditional ways of thinking on campus. These new challenges do not only impose on students and teachers but also on parents and school management.

The development of networks creates a vague physical boundary of a campus and allows greater affordance for learning. Students can now take lessons at home via a virtual classroom on high speed networks, search for information using various search engines at home via Internet, download teaching materials or read e-books at residential halls, etc. The popular use of mobile devices and tablet computers together with the high speed network provide not only a lot of learning opportunities but also distractions to students. Playing games, social networking, book readings, film watching and enjoying music are some of the favorite activities on these devices. One might argue that these activities even playing games can be educational but it all depends on the motivation of students, the availability of these educational materials in formats compatible to the devices and most importantly determination of students to learning on these devices.

Young people usually have the ability to grasp technologies much faster than teachers. Teachers, especially those more senior and more experienced, are now having a hard time in catching up with new technologies in their daily teaching and administrative work. Teaching materials and information prepared by teachers can now be easily obtained by students from various sources. This phenomenon in turn poses new challenges to teachers in terms of the changing roles from merely an information provider to a learning facilitator. Teachers are required to explore and discover new ways of learning together with students and to address problems arisen from learning difference.

Parents will have difficulties in knowing whether their children are playing or learning when using computers or mobile devices. This may enlarge further generation gap and miscommunication if not handled properly. But the use of new technologies does allow parents keeping track on progress of their children easily and enable better communication between students, parents and schools (Merkley et al. 2006).

Whether to allow students using mobile phones in schools becomes a sensitive policy. While mobile devices can be treated as a learning tool, it also creates other side effects when used improperly in schools. For example, making new friends with unknown background via social networking tools might be dangerous to children. When these new technologies are to be used in schools compulsory, this might also broaden the digital divide. 
There are difficult situations for educational authorities as well. When the great plans for developing information infrastructures are common, there are many information systems from various sources working in schools but there is still a lack of standards in educational data for planning, monitoring, analyzing and managing students and schools in a region. When these data are standardized, data of student performance may be able to transfer from one school to another.

\section{What kinds of intelligence are needed}

There are various stakeholders in education including students, teachers, parents, school management teams and education authorities. These stakeholders may have their own desires on the kinds of intelligence they need. Most students want their studies to be interesting, learning methods to be efficient, and information of a clear way in getting into a better school or a university for the next stage, if they are motivated.

Teachers want to have the intelligence in knowing the current state of student knowledge so as to apply the most suitable method to motivate or stimulate students' interest in learning. They may also want to know the latest development in the subject matter and be able to prepare a teaching session more efficiently and effectively. This effectiveness may be measured by whether a teaching session can engage students into deep learning. When answering questions from parents, teachers may want the intelligence on the whole picture on performance of the concerned student. One of the tasks that most teachers do not want to do is the school administrative work. Intelligent systems in schools are desired to allow teachers to perform their administrative duties more efficiently and wisely.

Parent wants to keep track on progress of children closely, preferably with alerts right before something goes wrong or when any deviation on normal behaviors is detected.

From school management teams' perspective, a school principal might want to have an overall picture on the daily operation of a school, including performance data of both students and teachers; together with ranking data comparing with other schools in the region or in the country. The school management team needs to find ways to predict the performance of students so as to increase the chances of their students getting into better schools or universities for their study next stage; or needs to respond intelligently to the requests from the local educational authority on various performance data.

The local educational authority however might be more concerned with obtaining reliable data from schools when needed for making policies and plans, monitoring the overall performance of schools in the region, analyzing this data and discovering any abnormal behaviors of schools.

In fact, these requirements on intelligence start with the requirements on information in the school environment.

\section{Possible research and development opportunities}

In order to obtain the kinds of intelligence we discussed earlier, there are some technologies in need. Current researches indicate that some possible research and development opportunities we discuss here are underway. There are a few areas of researches we want to mention, learning management systems (LMS) and knowledge management, 
personalized learning, adaptive learning and e-portfolio, immersive educational space, and safe learning environment.

In working with LMS, there are currently standards of learning object metadata (LOM) (Dublin Core; IEEE LTSC; IMS Learning Design Specification), which allows the description of learning objects (contents). However, these metadata consists of far too many data fields for learning designers to fill in. Intelligence on auto-extraction of keywords, video indexing etc. would be desirable. It is also desirable to have a knowledge competence model of subject matters, on which learning objects can fit in. Current practice treats LMS as a repository of learning objects relating only to specific courses and programs of study. It is seldom to find the use of LMS to be extended to apply the concept of knowledge management. For example, when conducting a research study, it might be desirable to have all the project documents, artefacts such as project plan, reports, design documents, design specification, and reference literatures to be treated as learning objects and have they described using LOM (Kwok and Cheung 2007); Kwok et al. (2008). A clear description of intended learning outcomes for learning objects with reference to the knowledge competence model may allow linkages between the state of student knowledge and LMS.

Personalized learning is a board term which includes personalized study plan and learning path, personalized information gathering and learning resource retrieval, and personalized learning activities. Setting personalized learning goals and learning path in order to obtain the right resources is desirable for smart learners. Mapping the personalized learning goals with the description of intended learning outcomes for learning objects, mechanisms for determining the learning path together and available learning objects can be identified, then obtaining the right learning resources from LMS can be automatic (Kwok et al. 2009). Intelligence on determining the level of competence of students is required and linkages between student management system and LMS are required. Retrieving personalized information is a skill required by all learners, including teachers. This information may contain information and knowledge essential to their study and career. Intelligence on the current state of one's knowledge, the personal preference and linkage to the domain knowledge ontology are desirable. Personalized learning activities may be a possible way to deal with individual learning difference. When students were affected by emotional factors or distraction to learning was detected, alternate learning scenarios may be generated so that students may find the alternate way of learning more interesting and thus, may concentrate on the study. In this regard, intelligence on various sensors detecting and determining changes on emotions is required. When a student finds a topic too easy, one may get a set of more difficult questions to solve; but in the case of finding it too difficult, one may obtain some supplementary learning materials to clear the obstacles. Intelligence on determining a level of competence according to the subject matter ontology is desirable.

Adaptive learning refers to the fulfilment of dynamic needs of learners and provision of feedbacks to the current state of learning in a smart learning environment. It can be treated as a special form of personalized learning in providing learning materials adaptively according to the competence level of learners in certain defined learning paths. Adaptive learning can also be in the form of intelligent tutoring systems which provide dynamic feedbacks to learning situations according to expert knowledge of learning domains and the current learning state of learners (Carbonell 1970; Sleeman and 
Brown 1982; Wenger 1987). Providing intelligent support and adaptive features in current learning systems has been reported in different contexts and settings, ranging from provision of courses and assessment in a range of learning environments that support collaborative, informal, ubiquitous learning (Brusilovsky et al. 1996; Graf et al. 2012; Zhuang and Kwok 2013).

Maybe e-portfolio is an ideal place to link all artefacts relating to personalized learning. These artefacts may include learning goals, plans, learning paths, learning activities, level of competence, learning performance and reflection, etc. However, it would be an added advantage to include extra-curricular activities as part of the learning activities for whole person development (Kwok and Chan 2012). Intelligence on modeling the relationships of learning goals, learning outcomes and learning activities is then required.

However, integrating different systems together in providing a personalized learning environment requires a lot of efforts in addressing issues in interoperability. The IMS Learning Tools Interoperability (LTI) standard (IMS Learning Tool Interoperability) aims to establish a standard way of integrating various learning applications with platforms like learning management systems (LMS), portals, or other educational environments. Attempts have been reported on using IMS LTI standard in integrating e-Portfolio system to LMS (Queirós et al. 2011), providing interoperability solutions for open learning environments and assessments (Alario-Hoyos et al. 2013; Conde et al. 2011; Garcia-Penalvo et al. 2011).

Immersive educational space allows a mixed virtual and reality environments for learning intelligently which may provide a sense of "being there" and thus enrich the learning experience (Hew and Cheung 2010; Ip and Kwong 2006). An associated set of new approaches, including underpinning theories, human factors, pedagogies, design and evaluation strategies, etc., for teaching and learning in this environment needs to be developed. Intelligence on detecting the conditions for switching to different scenarios is required.

Safe learning environment also requires a high level of automation and intelligence. Basic functions like access control to facilities, campus surveillance and monitoring can be easily implemented. However, it might not be easy to strike a balance between security and user friendliness in achieving security objectives. Can attendance taking automatically without user notice? Can abnormal situations or intrusion to campus be detected automatically? These functions cannot be achieved without intelligence on profiling normal and abnormal situations.

The above mentioned research and development opportunities are by no mean an exhausting list. Although some of the works have been conducted for a while, these researches are isolated efforts and putting all these together to have them applicable on a campus is still a long way to go.

\section{Smart examples in digital campus}

Smart can be considered as, according to some on dictionaries, very good at learning or thinking about things, showing intelligence or good judgment, or quick in action in handling problems. When a system can provide what you need according to the dynamic need of users, it can be considered as smart. In this section, we describe examples of systems in a digital campus to illustrate some smartness or intelligence. 
The School Administration and Management Systems (SAMS) project was launched in 1994, aiming to support all schools in Hong Kong in administrative and managerial tasks as a result of the government policy support coupled with heavy investment of building information infrastructures and applying information technology in schools (Manpower Bureau 1988; Tung 1997). However, despite of the massive government spending in developing some schools information systems, the effects of computerization of the school administrative and management process were found unsatisfactory. Teachers felt that those systems increased their workload heavily and the gathering and processing of student related data were performed with pain (Kwok et al. 1999). The student performance monitoring system (SPM-Net) (Kwok et al. 2000) was built with this background in the late 90's with an aim to develop a web-based system which integrated a range of functional areas dynamically so as to allow teachers performing their tasks in a smarter way. The examples in this section are based on the experience of the SPM-Net development.

\section{Knowing what to do next}

Our first example is an attendance system of a school. Normal attendance taking will take place when a teacher comes into a class. There are legislative requirements on reporting absence of students by schools. Normal attendance taking procedures will record all presence of students. However careful observations indicate that majority of students are present in most of the cases and absence is exceptional. Instead of recording the presence of students, the system was designed to record student absence. In addition, the linkage of the attendance system to timetabling data and seating plan of classes enabled it to show the seating plan with student photos. A teacher may then look at the seating plan, compare it with the empty seats in the class, and record the absence of students in seconds. The system will present the right seating plan of the right class to the teacher dynamically according to the timetable; especially students were allocated to a class every year according to their competence of a subject. Knowing what to do next is one of the features of smartness of the system.

\section{Comprehensive analysis}

Extra-curricular activities are an important part of learning and schools encourage student participation as part of the whole person development. Students do not only join these activities but also take part as organizers or leaders. When managing these activities, the required system needs to take into considerations of various forms of activities, a variety of posts for student leaders or organizers, level of attendance and participation of students, etc. To avoid having too many and inconsistent inputs to the system, the designers have all the posts of student leaders for all activities listed in the system for formulating teams systematically every semester. The comprehensive list of posts of all activities was resulted in good analysis of the user scenarios.

\section{Data on demand}

Student record card systems manage all record cards of students in a school. When a teacher produces comments on a record card for a student in a class, the teacher does not only need comments on academic results but also on attitudes, awards and 
punishment, and extra-curricular activities. The comment component of a student record card could provide choices of comments according to categories such as academic, behaviors, communication skills, participation in extra-curricular activities etc. and the level of achievements, which again as a result of detailed analysis. However, the teacher may also want to make an informed decision on producing the comments for students. The dynamic linking of the data to the record card system might provide teachers with all the necessary data so as to have a picture of the overall performance of a student before making the comments.

\section{Flexibility}

Different schools might have their own awarding schemes so as to encourage students reading or participating in social services. Despite local educational authorities tended to provide a unified template on school administrative systems so that all schools were molded to have the same functions, these school-based components can be built with the provision of a flexible template. This flexible template provides all the necessary elements for customization to different schemes by individual schools.

\section{Common characteristics}

The above examples show some of the characteristics of smartness of the systems on campus: the ability to know what a user want to do next at what place, the quick response to the need of a user by providing the necessary data, the ability of modeling structured procedures with flexibility.

\section{From digital campus to intelligent campus}

We have discussed the requirements on intelligence and their relating research and development opportunities in the previous section. In order to build an intelligent campus, we need to find out where the required intelligence may come from. Examples of smart systems described earlier show that smartness or intelligence is based upon availability of data. Intelligence is built on top of known procedural knowledge. Intelligence is also built on top of integration of existing automated systems merging with human intelligence. In this section, we discuss some elements essential in constructing intelligent campus: data considerations, procedural knowledge and system integration.

\section{Data considerations}

Availability of data is one of the most important factors in constructing intelligent systems. There are three elements in data considerations: data requirement and planning, data collection and data applications.

In terms of data requirements, the necessary data in producing the kinds of intelligence required by different stakeholders, as discussed in What kinds of intelligence are needed, needs to be analyzed. In outcome-based education, we are looking for evidence of achievements of students in various aspects. This evidence can only be supported with a large amount of data coming not only from course-embedded assessment but also participation in extra-curricular activities and their self-reflections relating to the learning goals. Data can also be obtained in different processes, 
including teaching and learning, co-curricular activities, performance measurement for students, teachers and schools, in educational establishments. In dealing with this vast amount of data from different sources, it is the responsibility of educational authority at a higher hierarchy to clearly define a standard for data requirements for the region according to the need of planning and monitoring. A unified standard enables data can be collected and compared in the same format.

There are many ways in data collection: compulsory or voluntary provision and sensor collection. Personal data in student records may be collected by compulsory form filling at the beginning of an academic year. Teaching and learning surveys are usually submitted voluntarily. Pictures captured by CCTV cameras, log data from physical access control points, sensors data from an immersive educational space, and Internet usage data relating to learning may be considered as data collected through sensors. The level of automation in collecting these data and converting them into a unifying format is an important step in such development.

The application of educational data can be various and its range of applications really depends on the imagination of users. In general, after processing these data captured from various sources, it may hopefully generate useful information and messages to the authority. This can be in the forms of overall pictures of students, teachers or schools. This information can also be in the form of indicators and trends of the performance with benchmarks to their respective counterparts; or in the forms of factors affecting student learning such as family background and regional difference etc.

As intelligence or smartness depends on the availability of a large amount of data, in particular personal data with subjective judgments, data privacy is a big concern. According to the definition in the Data Protection Act (Information Commissioner's Office Key Definition of Data Protection Act UK http ico org uk for_organisations data_protection the_guide key_definitions), personal data means data which relate to a person who can be identified from those data including any expression of opinion about the individual and any indication of the intentions of the data controllers or data users in respect of the individual. Educational establishments must follow the respective legislative requirements and the stated data protection principles in handling data.

\section{Procedural knowledge}

In the previous section, we mentioned the collection of data from various processes in educational establishments. The construction of systems in handling these data for the digital campus involves a certain level of automation on human procedures. Usually the mechanical part of human procedures can be easily identified. When subjective judgments and decision making are involved in these processes, its automation requires the extraction of implicit knowledge of the decision makers. Only when this implicit knowledge can be extracted, an increased level of automation can be added to the procedural knowledge that is, adding intelligence to existing systems. The automation of the decision making process also involves the ability of linking data from various sources dynamically so that an informed decision can be made. During the process of campus automation, whether it is a digital campus or an intelligent campus, it involves changes in manual procedures, working habits and cultures of educational establishments. A good practice in change management together with sufficient training and supports to teachers are necessary conditions to the successful implementation of intelligent campus. 


\section{System integrations}

There are many systems available in current practice of digital campus, including learning management systems, school management schools, student record systems, facility management systems, information security management systems, etc. These systems were designed for their respective purposes at various times. Integration of these systems to allow data from these systems be linked dynamically will certainly produce more useful information and thus be able to increase the level of automation and the level of smartness in a digital campus.

\section{Evolving processes}

Intelligent campus is not to be constructed from sketch but can only be built upon existing infrastructures and existing systems on a digital campus. However, there is no fast track to move from a digital campus to an intelligent campus. The gradual changes and improvement on existing systems and increasing their levels of automation and intelligence seem to be an inevitable trend on the development of intelligent campus. In between digital campus and intelligent campus, there appears a long evolving process of developing a smart campus which makes systems in a digital campus work cleverer and smarter.

\section{Conclusion}

The development in information and communication technologies induces a lot of changes in learning paradigms and creates new challenges on traditional campus at the same time. Different stakeholders on campus will have to face these challenges and have their own concerns respectively and thus require different kinds of intelligence when engaging on campus. There are some possible research and development opportunities relating to the development of intelligent campus which may include learning management systems and knowledge management, personalized learning, adaptive learning and e-portfolio, immersive educational space, and safe learning environment. Some examples of smarter systems on a digital campus were described to illustrate their characteristics based on the author's previous experience. The essential elements in the development of intelligent campus include data considerations, procedural knowledge and system integrations. There are privacy concerns when dealing with a large amount of personal data during this process. These data must be handled according to legislative requirements. The development of intelligent campus is an evolving process of which the transition from a digital campus to intelligent campus might take a long time. The speed of development depends on the current level of process automation and system integration. Increasing the level of automation and adding intelligence to existing systems to make them smarter require a large amount of work on extracting knowledge from human intelligence, and thus, a smart campus might be a prolonged stage in between.

There are some elements which may facilitate the process of achieving intelligent campus. A good supporting infrastructure is an important element. This supporting infrastructure does not only include networks, computers, systems and processes, but also involves people as part of the infrastructure. Automation of systems and processes requires a large amount of work in knowledge extraction on human intelligence. 
Without the necessary support and training to these people working on intelligent campus, the systems and processes will not be able to work effectively as they should be. A clear policy from a higher authority in supporting the development of intelligent campus, preferably as part of the plan in smart city development, is an essential assurance to its success.

In order to facilitate system integration, data from various systems needs to be interoperable. It is important that educational authorities at various levels define and publish education data standards according to their respective requirements so that various stakeholders can develop their systems with data interoperability according to the standard. The system developers together with educational experts may want to explore various ways in collecting data from the teaching and learning process in learning environments using various sensors and from LMS. These big data can then be analyzed and the results of such analysis can be provided as useful feedbacks to the teaching and learning practice. The technological changes in building smarter learning environments will inevitably induce changes to teaching and learning practice and behaviors, which in turn lead to the requirements in modifying existing, or establishing new educational management systems to cope with the changing practice in teaching and learning as well as in administrative processes.

During the process of migrating from a digital campus towards an intelligent campus, more and more data are to be collected and generated from our children. Teachers tend to be the agents in this process who will help in data collection, analysis and processing. Their work may become more reliant on the availability of such data. It is important that educational authorities should not treat children as data and teachers as tools. It is also important for teachers in this evolving process not to forget their roles (Han $\mathrm{Yu}$ ) in propagating the doctrine, imparting professional knowledge and resolving doubts.

Competing interests

The author declares that he has no competing interests.

\section{Acknowledgements}

This paper is based on the invited presentation made at International Forum of Education Technology (ETIF 2013).

Received: 17 July 2014 Accepted: 7 January 2015

Published online: 31 January 2015

\section{References}

C Alario-Hoyos, ML Bote-Lorenzo, E Gómez-Sánchez, Jl Asensio-Pérez, G Vega-Gorgojo, A Ruiz-Calleja, GLUE!: an architecture for the integration of external tools in virtual learning environments. Comput. Educ. 60, 122-137 (2013). Elsevier

A Boulton, SD Brunn, L Devriendt, Cyberinfrastructures and "smart" world cities: physical, human, and soft infrastructures, in International Handbook of Globalization and World Cities, ed. by B Derudder, M Hoyler, PJ Taylor, F Witlox (Edward Elgar Publishing, Cheltenham, UK, 2012)

P Brusilovsky, E Schwarz, G Weber, Elm-Art: An Intelligent Tutoring System on World Wide Web, in International Conference on Intelligent Tutoring Systems, LNCS 1086, ed. by C Frasson, G Gauthier, AM Lesgold (Springer, Montreal, Canada, 1996), pp. 261-269

A Caragliu, C Del Bo, P Nijkamp, Smart cities in Europe. J. Urban Tech. 18(2), 65-82 (2011). Taylor \& Francis

JR Carbonell, Al in CAl: artificial intelligence approach to computer assisted instruction. IEEE Trans. Man. Mach. Syst. 11(4), 190-202 (1970)

Centre of Regional Science, Vienna UT, (2007), Smart cities: Ranking of European medium-sized cities Final Report. http://www.smart-cities.eu/

Y Chen, Y Wang, X Li, L Gao, The Design and Implementation of Intelligent Campus Security Tracking System Based on RFID and ZigBee, in Proc. Second International Conference on Mechanic Automation and Control Engineering (MACE 2011) (IEEE, Inner Mongolia, 2011), pp. 1749-1752. 15-17 July 2011

Y Chen, R Zhang, X Shang, S Zhang, An Intelligent Campus Space Model Basedon the Service Encapsulation, in LISS 2012: Proc. 2nd International Conference on Logistics, Informatics and Service Science (Springer, Berlin Heidelberg, 2013), pp. 919-923 
MA Conde, FJ García-Peñalvo, M Alier, Interoperability Scenarios to Measure Informal Learning Carried out in PLEs, in Proc. Third International Conference on Intelligent Networking and Collaborative Systems (IEEE, Fukuoka, Japan, 2011), pp. 801-806. 30 November -2 December 2011

Dublin Core, http://dublincore.org/

FJ Garcia-Penalvo, MA Conde, M Alier, MJ Casany, Opening learning management systems to personal learning environments. J. Univers. Comput. Sci. 17(9), 1222-1240 (2011)

S Graf, F Lin, A Kinshuk, R McGreal, Intelligent and Adaptive Learning Systems: Technology Enhanced Support for Learners and Teachers (IGI Global, Hershey, PA, 2012)

Han Yu (AD 802), On the Teacher.

KF Hew, WS Cheung, Use of three-dimensional (3-D) immersive virtual worlds in K-12 and higher education settings: a review of the research. Br. J. Educ. Tech. 41(1), 33-55 (2010). Wiley

B Hirsch, JWP Ng, Education beyond the cloud: anytime-anywhere learning in a smart campus environment, in Proc. International Conference for Internet Technology and Secured Transactions (ICITST 2011) (IEEE, Abu Dhabi, UAE, 2011), pp. 718-723. 11-14 December 2011

IEEE LTSC, http://ieee-sa.centraldesktop.com/ltsc/

IMS Learning Design Specification, http://www.imsglobal.org/learningdesign/

IMS Learning Tool Interoperability, http://www.imsglobal.org/toolsinteroperability2.cfm/

Information Commissioner's Office. Key Definition of Data Protection Act UK. https://ico.org.uk/for-organisations/guide-to-data-protection/key-definitions/

HHS Ip, B Kwong, Smart Ambience Games for Children with Learning Difficulties, LNCS 3942 - Technologies for E-Learning and Digital Entertainment: First International Conference, Edutainment 2006, April 16-19 (Springer, Hangzhou, PRC, Berlin Heidelberg, 2006)

M Jackson, Intelligent Campus, Proc. 1st International Symposium on Pervasive Computing and Applications (IEEE, Urumchi, Xinjiang, China, 2006), p. 3. 3-5 August 2006

N Komninos, Intelligent cities: towards interactive and global innovation environments. Int. J. Innovat. Reg. Dev. 1(4), 337-355 (2009). Inderscience Publishers

LF Kwok, KS Chan, Building an e-portfolio with a learning plan centric approach. J. Zhejiang Univ. Sci. C. (Computers \& Electronics) 13(1), 37-47 (2012). Zhejiang University and Springer-Verlag

LF Kwok, CH Cheung, An ontology-based approach to project-based learning, in Proc. 10th IASTED Int. Conf. On Computers and Advanced Technology in Education - Globalization of Education Through Advanced Technology (CATE 2007), 8-10 October 2007, ed. by V Uskov (PRC, Beijing, 2007), pp. 389-394

LF Kwok, CK Lau, SW Fung, Evaluating SAMS in Hong Kong Schools. Comput. Educ. 32(3), 249-267 (1999). Elsevier

LF Kwok, MT Chan, HHS Ip, A Web-based Student Performance Monitoring System, in Proc. World Multi-conference on Systemics, Cybernetics and informatics (SCI 2000) and 6th International Conference on Information Systems Analysis and Synthesis (ISAS 2000), vol. 1 (IIIS, Orlando, Florida, USA, 2000), pp. 342-346. 23-26 Jul 2000

LF Kwok, CH Cheung, WS Tsoi, Applying Ontology in a Project-Based Learning Environment (Proc. 16th Int. Conf. on Computers in Education (ICCE 2008), Taipei, Taiwan, 2008), pp. 551-555

LF Kwok, SY Yeung, CH Cheung, A training path advisor for lifelong learning, in Proc. 8th IASTED Int. Conf. On Web-Based Education (WBE 2009), 16-18 Mar 2009 (ACTA Press, Phuket, Thailand, 2009), pp. 84-89. ISBN (CD): 978-0-88986-789-5

P Lombardi, S Giordano, H Farouh, W Yousef, Modelling the smart city performance: Innovation. Eur. J. Soc. Sci. Res. 25(2), 137-149 (2012). Routledge

Education and Manpower Bureau (1988), Information Technology for Learning in a New Era - Five-year Strategy: 1998/99 to 2002/03, HKSAR Government.

D Merkley, D Schmidt, C Dirksen, C Fuhler, Enhancing parent-teacher communication using technology: a reading improvement clinic example with beginning teachers. Contem. Issues Tech. Teach. Educ. 6(1), 11-42 (2006). AACE

T Nam, TA Pardo, Conceptualizing smart city with dimensions of technology, people, and institutions, in Proc. $12^{\text {th }}$ Annual International Digital Government Research Conference: Digital Government Innovation in Challenging Times (ACM, New York, 2011), pp. 282-291

JWP Ng, N Azarmi, M Leida, F Saffre, A Afzal, PD Yoo, The Intelligent Campus (iCampus) End-to-end learning lifecycle of a knowledge ecosystem, in Proc. Sixth International Conference on Intelligent Environments (IEEE, Kuala Lumpur, Malaysia, 2010), pp. 332-337. 19-21 July 2010

N Odendal, Information and communication technology and local governance: understanding the difference between cities in developed and emerging economies. Comput. Environ. Urban. Syst. 27(6), 585-607 (2003). Elsevier

R Queirós, L Oliveira, JP Leal, F Moreira, Integration of ePortfolios in Learning Management Systems, in ICCSA 2011, Part V, LNCS 6786, ed. by B Murgante et al. (Springer, Berlin Heidelberg, 2011), pp. 500-510

DH Sleeman, JS Brown (eds.), Intelligent Tutoring Systems (Academic, New York, 1982)

CW Tung, The First Hong Kong Special Administrative Region Policy Address (Government, HKSAR, 1997)

E Wenger, Artificial Intelligence and Tutoring Systems: Computational and Cognitive Approaches to the Communication of Knowledge (Morgan Kaufmann, Los Altos, CA, 1987)

JV Winters, Why are smart cities growing? Who moves and who stays. J. Reg. Sci. 20(10), 1-18 (2010). Wiley

T Yigitcanlar, K Velibeyoglu, Knowledge-based urban development: the local economic development path of Brisbane, Australia. Local Econ. 23(3), 195-207 (2008). Sage Publications

Y Zhuang, LF Kwok, "Developing an intelligent tutoring system for Sudoku on Mobile Platform", Information. Int. Interdiscipl. J. 16(8B), 6149-6158 (2013). Japan: International Information Institute 